\title{
Expropiación forzosa
}

\author{
Caducidad de disposiciones que ordenan una expropiación. Abandono \\ Y renovación del procedimiento respectivo.
}

Por el Dr. CESAR BARROS CONTI

En el mes de Mayo último, con ocasión del desempeño de un cargo que en la actualidad no ejerzo, tuvo a la vista cierto expediente administrativo en el que se solicitaba la renovación de un procedimiento de expropiación. Esta circunstancia me brindó la oportunidad de realizar un estudio de la caducidad de disposiciones que ordenan una expropiación, del abandono y de la renovación del procedimiento respectivo, encontrando la existencia de una irregular y oscura situación, cuya regularización debe hacerse.

En efecto, el artículo $8^{\circ}$ de la ley 9125 dispuso textualmente que "fijado el valor que debe abonarse por el bien materia de la expropiación, ya sea por allanamiento del propietario o por acuerdo del perito de éste con la valorización de los Ingenieros del Estado, o por el perito dirimente a que se refiere el artículo $22^{\circ}$, el expropiante deberá consignar dentro de tercero día dicho precio en la Caja de Depósitos y Consignaciones, a la orden del Juzgado. Vencido este término y después de un requerimiento, si no se ha formalizado la consignación, se tendrá por abandonado el procedimiento de la expropiación, el cual no podrá renovarse sino después de un año".

El mencionado dispositivo fué modificado totalmente por la ley 11549, promulgada el 18 de Diciembre de 1950, la cual establece en su artículo único que: "fijado el valor que debe abonarse por el bien materia de la expropiación, ya sea por allanamiento del propietario o por acuerdo del perito dirimente a que se refiere el $A r^{\circ} 22^{\circ}$. , el expropiante deberá consignar dentro de tercero día dicho precio en la Caja de Depósitos y Consignaciones, a la orden del Juzgado. Vencido este término y después de un requerimiento, si no se ha formalizado la consignación, se tendrá por abandonado el procedimiento seguido y por caducada y sin efecto la disposición que ordenó la expropiación".

La modificación pues consiste fundamentalmente en derogar la re- 
novación del procedimiento de expropiación, teniéndose para lo sucesivo no sólo por abandonado dicho procedimiento sino por caducada y sin efecto la disposición que ordenó la expropiación si, vencido el término procesal de tercero día y después de un requerimiento judicial, el expropiante no cumpliera con consignar el precio en la Caja de Depósitos y Consignaciones $\alpha$ la orden del Juzgado.

Por manera pues que, cuando menos desde ese 18 de Diciembre de 1950, la ley no establece ya disposición alguna en virtud de la cual pueda renovarse un procedimiento de expropiación; por el contrario, debe tenerse definitivamente por abandono éste y por caducada y sin efecto la disposición que le dió origen, si no se llega a formalizar la consignación dentro de ese breve término y luego de un requerimiento judicial. Pero, antes de cumplirse cuatro meses de promulgada esa ley 11549, el 13 de Abril de 1951 se expidió el decreto supremo $\mathrm{N}^{\circ} 41$, estableciendo éste que los decretos y resoluciones supremas que ordenaban una expropiación o reconocieran su utilidad o necesidad pública, quedan sin efecto si transcurridos dos años de su expedición no se iniciara el procedimiento indicado en el Art. $4^{\circ}$ de la ley 9125, ni se consignara el precio "como lo manda el Art. $8^{\circ}$ de la misma ley".

Este decreto supremo agrega que, producida así la caducidad, no podrá renovarse el procedimiento de expropiación ni declararse nuevamente la necesidad y utilidad de una propiedad privada, sino después de transcurrido el plazo de un año "que menciona el citado Arto 8 \%. de la ley 9125", indicando seguidamente la forma de procederse "en estos casos de reiteración".

Agrega luego esta misma disposición administrativa que las oficinas del Estado y de las Municipalidades no podrán negar permisos de reconstrucción, refacción, demolición, venta, etc., de inmuebles, alegando la existencia de declaración de necesidad y utilidad, si se hubieran vencido los plazos que indica; $y$, finalmente, extiende sus alcances a resoluciones de expropiación y declaración de necesidad y utilidad pública "anteriormente dictadas".

Por último, la ley 12031, de 23 de Diciembre de 1953, se ha dado en el sentido de adicionar al Art. $8^{\circ}$ de la ley 9125 un texto en virtud del cual se tendrá por caducada y sin efecto la disposición que ordenó la expropiación, si no se terminaran los trámites ni se consignara el precio den. tro de los dos años de la fecha en que aquélla fué expedida.

Tales son, pues, las disposiciones en vigor $y$ que se ocupan de la caducidad de las que ordenan una expropiación y del abandono y renovación del respectivo procedimiento; pero, al respecto, me permito formular las siguientes observaciones:

A. - Si en virtud de la ley 11549 el abandono del procedimiento de expropiación y la caducidad de la disposición que le diera origen se producen, simultáneamente, después de un requerimiento para que el expro. piante cumpla con consignar el precio por no haberlo hecho dentro del término de tercero día; y, modificando totalmente el arto $8^{\circ}$ de la ley 9125 , se deroga la renovación del procedimiento, no resulta jurídicamente posible que, por el sólo mérito de un decreto supremo, se modifique esa ley 
estableciéndose administrativamente que la caducidad se produciró transcurridos dos años de expedida la disposición que ordenó la expropiación, sî no se hubiera iniciado el procedimiento y consignado el precio.

Visto que una ley sólo puede ser derogada o modificada por otra, lo dispuesto en virtud del mencionado decreto supremo $N^{\circ} 41$, de 13 de Abril de 1951, no tiene mérito alguno frente a la provisión contenida en la ley 11549, de 18 de Diciembre de 1950.

B. - La ley 11549 parece haber sido olvidada no solamente por el aludido decreto supremo sino también por la ley 12031, posteriormente promulgada el 23 de Diciembre de 1953.

En efecto, dicho decreto supremo se remite hasta dos veces al "artículo $8^{\circ}$ de la ley $9125^{\prime \prime}$, sin tener en cuenta que, sólo cuatro meses antes de expedido, fué promulgada la ley 11549 que modificó totalmente ese artículo; $\mathrm{y}$, la ley 12031, promulgada tres años y cinco días después de la ley 11549 modificatoria del Art $8^{\circ}$. de la ley 9125, le hace a esta última una adición que resulta, por lo mismo que no tuvo en consideración la circunstancia que dicho artículo fuera modificado legalmente, total y completamente inoperante.

C.- Siendo así que la ley 11549, al modificar totalmente el Art?. $8^{\circ}$. de la ley 9125, suprime toda posible renovación, no puede legalmente admitirse que sólo por el citado decreto supremo se modifique el status legal, disponiendo ese decreto que podrá renovarse el procedimiento en la forma que lo hace en su Art" $2^{\circ}$., al expresar textualmente: "después de transcurrido el plazo de un año que menciona el citado art ${ }^{\circ}$. $8^{\circ}$. de la ley 9125", por cuanto éste fué legalmente modificado, como se ha visto, ni por cierto estableciendo el mismo decreto normas para "estos casos de reiteración". No está de más anotar que ese decreto llega al extremo de disponer finalmente que sus provisiones tienen efectos retroactivos, cuando estatuye que en sus alcances quedan comprendidas las disposiciones de expropiación que anteriormente hubieran sido dictadas.

D. - La ley 12031, de 23 de Diciembre de 1953, establece una disposición en realidad inoperante, porque su provisión es inadecuada y contradictoria.

Efectúa una adición al art ${ }^{\circ}$. $8^{\circ}$. de la ley 9125, olvidando que este artículo fué modificado por la ley 11549. Sin embargo, aún cuando para nada se refiere a ésta, podría interpretarse que la adición la efectúa al $a^{\circ}{ }^{\circ} .8^{\circ}$. de la ley 9125, modificado por la ley 11549.

Estudiando estos supuestos, resulta:

a.- Que si el art'. 8\%. de la ley 9125 estableció que de no formalizarse la consignación después de un requerimiento al expropiante, por no haberla efectuado dentro de tercero día de fijado el valor, se tendría por abandonado el procedimiento y su renovación sólo podría hacerse después de un año, mal puede efectuarse la adición para que se tenga por caducada y $\sin$ efecto la disposición que ordenó la expropiación si dentro del plazo de dos años de expedida no quedaran terminados sus trámites ni consignado el precio de la misma, porque este plazo de caducidad bien 
puede producirse antes de vencerse el de un año para pedirse la renovación; y, así, resulta en este caso inoperante esta adición, $y$,

b.- Que de interpretarse la adición como efectuada en realidad a la ley 11549, modificatoria del art ${ }^{\circ}$. de la ley 9125, la evidente $y$ visible contradicción con lo dispuesto en esa ley anterior hace aún, si cabe, más inoperante é inaplicable la adición, al efectuarse sobre un texto legal que establece tenerse por caducada y sin efecto la disposición que ordenó la expropiación sólo después de un breve término procesal.

La argumentación así expuesta, conduce a las siguientes conclusiones:

la.- El arto 8․ de la ley 9125 no legisló sobre la caducidad de la disposición expropiatoria, sino sólo sobre el abandono del procedimiento de expropiación, el cual se producía después de un requerimiento judicial para que el expropiante cumpliera con consignar el precio, por no haberlo hecho dentro del término de tercero día.

2a. - Ese mismo dispositivo legal previó también la renovación del procedimiento de expropiación, disponiendo que podría hacerse efectiva después de un año de producido el abandono.

3a. - La ley 11549, de 18 de Diciembre de 1950, deroga esa renovación de procedimiento y establece, en forma definitiva, la institución de la caducidad de la disposición, la que opera conjuntamente con el abandono del procedimiento.

4a.- El decreto supremo No 41, del 13 de Åbril de 1951, es ilegal porque sus disposiciones modifican $y$ contradicen el texto expreso de la ley $y$ es así que una ley sólo puede ser modificada ó derogada por otra, como lo expresa el art 1 ․ del Título Preliminar del Código Civil. En consecuencia, todas las disposiciones establecidas en dicho decreto y que se refieren lanto a la caducidad de la disposición, como a la renovación del procedimiento de expropiación y demás provisiones, son insubsistentes $\mathrm{y}$ no pueden ni deben aplicarse legalmente.

5a.- Siendo inoperante la ley 12031 al efectuar adición a una disposición insubsistente por su posterior modificación y al contradecir incluso el tenor de la ley modificatoria, la oscura situación actual debe ser legalmente esclarecida, tanto respecto del término vencido el cual se produce la caducidad, cuanto de la posibilidad de renovarse la expropiación; visto que, dados los antecedentes anotados, jurídicamente sólo debe tenerse en la actualidad, como normas legalmente aplicables, las previstas por la ley 11549: la caducidad se produce conjuntamente can el abandono del procedimiento, sin que exista posibilidad alguna de renovación.

$6 a$. - Se hace necesaria entonces la dación de una nueva ley que regularice esa oscura situación que existe respecto al término vencidc el cual debe producirse la caducidad y que defina la posibilidad de renovación del procedimiento de expropiación, visto que esta última institución fué prevista originariamente en el art. $8^{\circ}$ de la ley $9125 \mathrm{y}$, aquélla, incluída en esa misma disposición, al modificarla la ley 11549. 
Al leer en "El Comercio" de hoy (7 de octubre de 1961) que el Senado ha aprobado un proyecto de ley, cuya presentación fuera efectuada por el Senador Enrique Martinelli Tizón, derogando la ley 12031 que adiciona el vartículo $8^{\circ}$ de las leyes 9125 y 11549, sobre expropiación forzoza, pude de inmediato tenerlo a la vista ese mismo día, enterándome así que fué presentado el 14 de abril de 1958.

El proyecto aprobado tiene las siguientes consideraciones:

"Que la Ley No 12031, por la que se adiciona el artículo $8^{\circ}$ de la Ley $N^{\circ} 9125$ y la Ley modificatoria No 11549 sobre expropiaciones, en lugar de facilitar la tramitación adecuada y correspondiente del procedimiento expropiatorio, anula por razón de tiempo sus alcances."

"Que es bien conocida la demora del procedimiento que en si entraña la tramitación de las expropiaciones, por tener que referirse ellas $\alpha$ tasaciones y a actuados que demandan mucho tiempo."

"Que el plazo de dos años señalado por la Ley 12031 no tiene ninguna justificación, ya que dada una ley o resolución de expropiación, ésta debe cumplirse forzosamente sin taxativas".

"Que para desnaturalizar y lograr el incumplimiento de una ley do expropiación bastaría buscar medios de dilación para que se venza el plazo que señala la Ley 12031, burlando en dicha forma los alcances de cualquier expropiación."

"Que en resguardo de los intereses del Estado, es del caso dejar sin efecto dispositivos que enerven su acción legal; por lo que presento a la consideración del Senado el siguiente proyecto de ley."

No contiene el proyecto consideración juridica relacionada con la circunstancia que la adición efectuada por la ley 12031 consiste, en realidad, en establecer una disposición inoperante é inadaptable, siendo difícil de aplicarse tanto por ser inadecuada su provisión misma, cuanto por contradecir visiblemente el texto de la ley 11549 que modifica el artículo $8^{\circ}$ de la ley 9125. Tiene, sin embargo, el mérito de derogar expresamente esa contradictoria adición legal. De convertirse en ley, la caducidad de la disposición que ordenó una expropiación se producirá, simultáneamente con el abandono del procedimiento, después de un requerimiento judicial para que el expropiante cumpla con formalizar la consignación, si no lo hizo dentro de tercero día de fijado el valor, tal como lo establece la ley 11549 y cuyo tenor reemplaza al del artículo $8^{\circ}$ de la ley 9125; pero, como el proyecto no se refiere a la posibilidad de renovarse el procedimiento abandonado - posibilidad que contemplara originariamente el artículo $8^{\circ}$ de la ley 9125 y que fuera derogada por la ley 11549 - tal posibilidad sigue por ahora sin subsistir, aunque puedan ocurrir casos en los que se justifique la renovación.

No obstante, sin existir, como se vé, un fundamento legalmente válido, se solicita en la próctica la renovación del procedimiento abandonado. mediante la dación de una nueva declaratoria de necesidad y utilidad pública, precisamente en razón que la anterior disposición ha caducado por 
haberse vencido el término de los dos años de su dación. Y es curioso anotar que, tales solicitudes de reiteración, se basan en el aparente mérito del ilegal decreto supremo tantas veces citado y cuyas disposiciones, aún en vigor por no haber sido derogadas, mantienen no sólo la posibilidad de renovar el procedimiento - contrariando expresamente el tenor de la ley 11548 que deroga tal posibilidad é invocando, para éllo, el plazo de un año "que menciona el artículo $8^{\circ}$ de la ley 9135", vale decir, un texto que no subsiste - sino que, como se ha visto, contienen también el plazo de caducidad de dos años que después repitiera la ley 12031, cuya. derogatoria precisamente es materia del comentado proyecto de ley, además de tener ese mismo decreto supremo otras disposiciones, ilegales.

Por cierto, hay casos en que la renovación del procedimiento de expropiación se encuentra justificada. Como legalmente no subsiste esta posibilidad, sería interesante que la Cámara de Diputados la contemplara con motivo de debatirse en su seno ese proyecto de ley aprobado en el Senado, lográndose así que se adicione al tenor de la ley 11549, modificato. ria del Artículo $8^{\circ}$ de la Ley 9125, la frase: "El procedimiento podrá renovarse después de un año de producido el abandono" ú otra similar; debiendo el Poder Ejecutivo, de otra parte, proceder a derogar el decreto supremo. No 4l, de 13 de Abril de 1951 . 